\title{
Morphometric Evaluation of Occipital Condyles: Defining Optimal Trajectories and Safe Screw Lengths for Occipital Condyle-Based Occipitocervical Fixation in Indian Population
}

Aju Bosco ${ }^{1}$, Prakash Venugopal ${ }^{2}$, Ajoy Prasad Shetty ${ }^{1}$, Rajasekaran Shanmuganathan ${ }^{1}$, Rishi Mugesh Kanna ${ }^{1}$

${ }^{1}$ Department of Spine Surgery, Ganga Hospital, Coimbatore, India

${ }^{2}$ Department of Radiology, Ganga Hospital, Coimbatore, India

Study Design: Computed tomographic (CT) morphometric analysis.

Purpose: To assess the feasibility and safety of occipital condyle (OC)-based occipitocervical fixation (OCF) in Indians and to define anatomical zones and screw lengths for safe screw placement.

Overview of Literature: Limitations of occipital squama-based OCF has led to development of two novel OC-based OCF techniques.

Methods: Morphometric analysis was performed on the OCs of 70 Indian adults. The feasibility of placing a 3.5-mm-diameter screw into OCs was investigated. Safe trajectories and screw lengths for $\mathrm{OC}$ screws and $\mathrm{CO}-\mathrm{C} 1$ transarticular screws without hypoglossal canal or atlantooccipital joint compromise were estimated.

Results: The average screw length and safe sagittal and medial angulations for OC screws were $19.9 \pm 2.3 \mathrm{~mm}, \leq 6.4^{\circ} \pm 2.4^{\circ}$ cranially, and $31.1^{\circ} \pm 3^{\circ}$ medially, respectively. An OC screw could not be accommodated by $27 \%$ of the population. The safe sagittal angles and screw lengths for $\mathrm{CO}-\mathrm{C} 1$ transarticular screw insertion $\left(48.9^{\circ} \pm 5.7^{\circ}\right.$ cranial, $26.7 \pm 2.9 \mathrm{~mm}$ for junctional entry technique; $36.7^{\circ} \pm 4.6^{\circ}$ cranial, $31.6 \pm 2.7 \mathrm{~mm}$ for caudal $\mathrm{C} 1$ arch entry technique, respectively) were significantly different than those in other populations. The risk of vertebral artery injury was high for the caudal $\mathrm{C} 1$ arch entry technique. Screw placement was uncertain in $48 \%$ of Indians due to the presence of aberrant anatomy.

Conclusions: There were significant differences in the metrics of OC-based OCF between Indian and other populations. Because of the smaller occipital squama dimensions in Indians, OC-based OCF techniques may have a higher application rate and could be a viable alternative/salvage option in selected cases. Preoperative CT, including three-dimensional-CT-angiography (to delineate vertebral artery course), is imperative to avoid complications resulting from aberrant bony and vascular anatomy. Our data can serve as a valuable reference guide in placing these screws safely under fluoroscopic guidance.

Keywords: Occipital bone; Occipital condyle; Atlanto occipital joint; Occipitocervical fusion; Occipital condyle screw; C0-C1 transarticular screw

Received May 9, 2017; Revised Jun 25, 2017; Accepted Jun 28, 2017

Corresponding author: Ajoy Prasad Shetty

Department of Spine Surgery, Ganga Medical Centre and Hospitals Pvt. Ltd., 313, Mettupalayam Road, Coimbatore 641043, Tamil Nadu, India

Tel: +91-9344833797, Fax: +91-422-2451444, E-mail: ajoyshetty@gmail.com 


\section{Introduction}

Several pathologies such as trauma, rheumatoid arthritis, infections, tumors, congenital malformations, and degenerative conditions can lead to occipitocervical instability, wherein restoration of structural integrity and stability of the occipitocervical junction (OCJ) is important [1]. Surgical fixation of occipitocervical instability has advanced during the past decades, and occipital plate-rod-screw instrumentation is currently the most widely used method [2-4].

All currently available occipital squama fixation methods use the midline occipital keel to obtain good screw purchase. However, the thickness of the occipital plate in this region varies between $8-12 \mathrm{~mm}$ in adults, leading to a high incidence of failed occipitocervical fixation (OCF) because of poor screw hold or complications from inadvertent screw purchase, such as venous sinus injury, dural tear with cerebrospinal fluid leakage, and epidural hematoma [5]. However, there are unique situations that prevent the use of occipital squama-based fixations, such as posterior fossa craniectomy scenarios, tumors or infections of occipital bone, and previous failed occipital fixations due to pseudarthrosis or occipital bone erosion at screw purchase sites [6]. Therefore, there is a need to identify new fixation points at the craniovertebral junction as additional augmentive anchors or salvage fixation points.

Occipital condyles (OCs) form the keystone in maintaining the structural integrity and stability of OCJ. For many years, spine surgeons have declined to use OCs as viable structures for screw placement because of their complex anatomical location and critical neurovascular neighborhood comprising the vertebral arteries, spinal canal, hypoglossal canal, and jugular foramen [7]. With the advent of advanced neuroimaging and intraoperative neuronavigation, there has been more interest in identifying fixation points in areas that were previously considered dangerous to access or insufficient for bone anchorage.

Recently, two novel techniques of OCF, direct occipital condyles screw (OCS) and $\mathrm{C} 0-\mathrm{C} 1$ transarticular screw techniques, that use the OCs as alternative or augmented fixation points have been introduced [8-12]. Accurate knowledge of the orientation and dimensions of OCs and their relationship with the critical neurovascular neighborhood is important for the safe use of these novel techniques.

The feasibility and safety of these techniques have been investigated in different populations but not in Indian population, as per our knowledge [13-18]. Existing data on the morphometry of OCs in Indian population are mostly based on in vitro measurements on cadaveric or dry skulls [19-24]. The only available in vivo computed tomography (CT)-based study was conducted in a small sample population [25]. In the previous Indian studies, the samples were not uniformly distributed across all age groups or stratified according to sex. This could result in significantly higher complication rates in OCFs performed based on conventional anatomical data in Indian population.

We performed a CT-based morphometric analysis of OCs in the Indian population, aiming to create a normative reference database to aid in safe OC instrumentation. The study also aimed at investigating the feasibility and safety of OC-based OCFs in Indians and to define anatomical zones and screw lengths for safe screw placement. The study also provides a normative reference database of screw lengths and trajectories for OCS and $\mathrm{C} 0-\mathrm{C} 1$ transarticular screw fixations, stratified by age and sex.

\section{Materials and Methods}

The study was approved by the Institutional Review Board and Ethics Committee of Ganga Hospital, Coimbatore, India (IRB approval no., 17-S-4/2017). This was an IRBapproved, CT-based morphometric analysis of OCs in 70 Indian adults (20-65 years; mean, $42.1 \pm 14.6$ years) who underwent head and cervical spine scanning at Ganga Hospital, Coimbatore between March 2015 and August 2016. The exclusion criteria were as follows: skeletal immaturity, trauma (fracture at the craniocervical junction or upper cervical spine), neoplastic pathology, inflammatory disease, infection, congenital malformation, previous surgery, or deformity. Samples were chosen so that they were equally distributed $(n=7)$ across each age group $(20-29,30-39,40-49,50-59$, and $60-69$ years). Both condyles were evaluated for each patient, giving a total of 140 OCs for analysis.

\section{Morphometry-methodology}

Morphometric analysis was performed using helical thin-slice high-resolution CT (Siemens Medical Systems, Erlangen, Germany). Images were acquired in the picture archiving and communication system format; measurements were made after employing advanced 
three-dimensional (3D) volume reconstruction software (Advanced 3D software, Medsynapse; Medsynaptic Pvt. Ltd., Pune, India), which enabled precise 3D localization of the plane of evaluation. Linear (in $\mathrm{mm}$ ) and angular (in degrees) measurements were made on bone windows using the standard measurement palette of the Medsynapse software (Medsynaptic Pvt. Ltd.). Multiple measurements in the axial, sagittal, and coronal planes were obtained from the CT images at a resolution of $1.25 \mathrm{~mm}$. All measurements were made bilaterally. Each measurement was made independently by a radiologist and a spine surgeon to ensure reproducibility and to avoid interobserver variability. After the initial measurements were made, 20 cases were randomly chosen, and the values were remeasured to check reproducibility.

In the axial plane, the occipital condyle length (OCL) was measured along the long axis of the condyle, between its anterior and posterior midpoints (Fig. 1A). The occipital condyle width (OCW) was the widest distance from the medial to the lateral margin in the axial plane (Fig.
1A). The axial condyle angle was the angle formed by the long axis of the condyle with the sagittal midline (Fig. 1B). In the coronal plane, the medial and lateral condyle heights were measured from the point of OC attachment to the skull base up to the inferior margin of the condyle, (Fig. 1C). In the sagittal plane, the anterior and posterior condylar heights and the distance from the inferior margin of the condyles to the base of the hypoglossal canal were measured (Fig. 1D).

\section{Measurement of safe trajectories and safe screw lengths for occipital condyle screw placement}

The entry point of the direct OCS was chosen to be 2-mm cephalad to the posterosuperior margin of the $\mathrm{C} 0-\mathrm{C} 1$ joint in the sagittal plane (Fig. 2B), midpoint of the posterior surface of OCs in the mediolateral plane (which was approximately $5-\mathrm{mm}$ lateral to the posteromedial edge of the condyle at its junction with the foramen magnum in this study) (Fig. 2A) [9,10]. The screw trajectory was
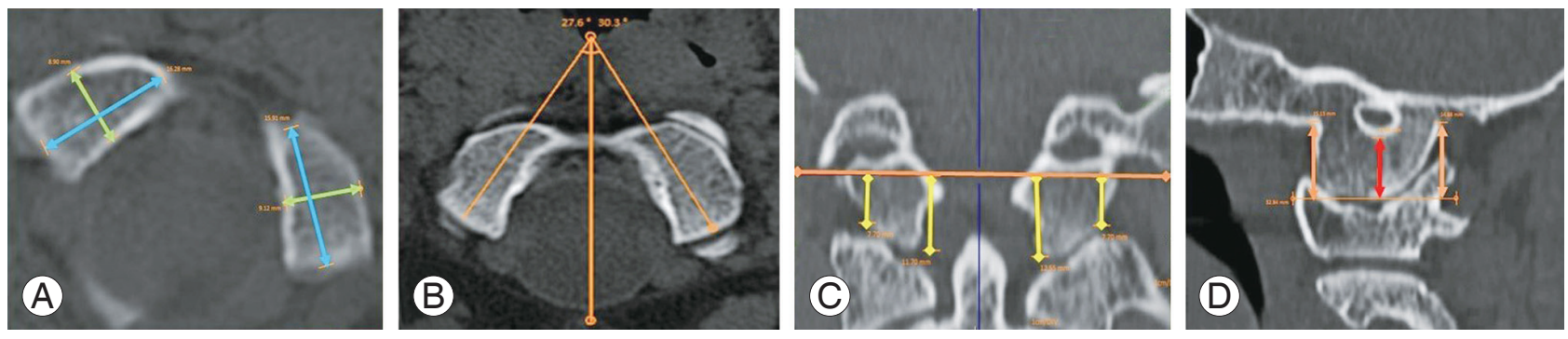

Fig. 1. Reconstructed CT images of the occipitocervical junction (bone window) depicting linear and angular measurements on the OCs in axial, sagittal, and coronal planes. (A) Axial CT image depicting the measurement of OC length (blue double-headed arrows) and OC width (green doubleheaded arrows) measurements. (B) Axial CT images depicting the measurement of axial OC angles of the right and left OCs. (C) Coronal CT images depicting measurements of medial OC height and lateral OC height at the medial and the lateral margins of the condyle (yellow lines). (D) Sagittal CT images depicting anterior condyle height and posterior condyle height (orange double-headed arrows) and the hypoglossal canal distance defined as the distance from the inferior most point on the condylar articular surface to the base of the hypoglossal canal (red double-headed arrow). CT, computed tomography; OC, occipital condyle.
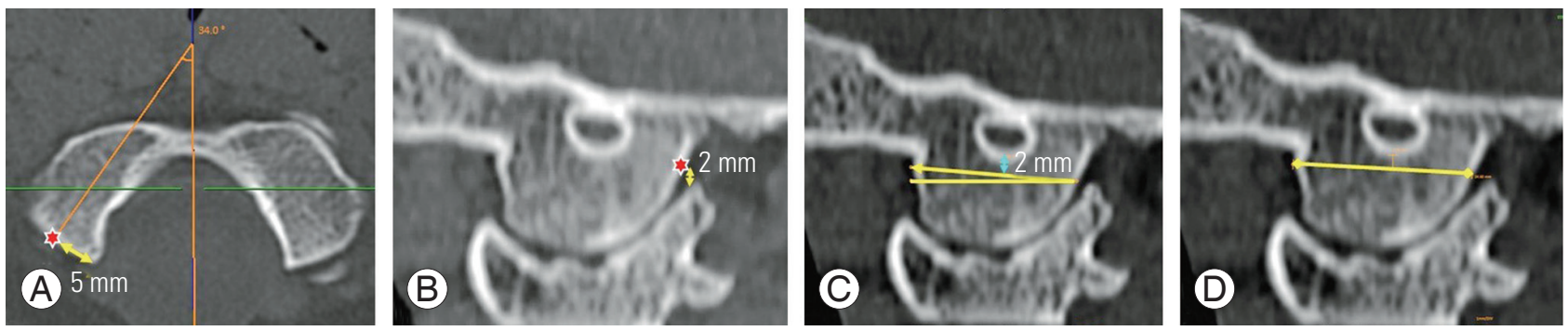

Fig. 2. (A) Axial CT image of OCs showing the entry point for OC screw (red asterisk) taken at the middle of the posterior surface of OC in the mediolateral plane. (B) Sagittal CT image of the occipitocervical junction showing the entry point (red asterisk) taken 2-mm cephalad to the posterosuperior aspect of the $\mathrm{CO}-\mathrm{C} 1$ joint. (C) Sagittal CT image depicting the safe sagittal angulation for an OC screw stopping 2-mm inferior to the hypoglossal canal and (D) the longest possible OC screw length with bicortical purchase along the same trajectory. CT, computed tomography; OC, occipital condyle. 
placed along the long axis of the condyle, and the targeted exit point was aimed toward the basion at the anterosuperior margin of the condyle. Three parameters for safe screw placement were measured: (1) the angle of screw medialization (angle formed by the long axis of a condyle with the sagittal midline) (Fig. 2A), (2) the maximum permissible safe sagittal angulation avoiding hypoglossal canal injury (cranial angulation was stopped at a point 2-mm inferior to the hypoglossal canal to allow a safety margin) (Fig. 2C), and (3) the longest possible screw length for bicortical anchorage (Fig. 2D) measured on the reconstructed oblique sagittal plane fitting the ideal trajectory of OCS in Indians.

\section{Optimal sagittal trajectory for the occipital condyle screw}

Based on previous published reports, we applied specific craniocaudal angulations $\left(10^{\circ}\right.$ and $5^{\circ}$ cranial angulation; $5^{\circ}$ and $10^{\circ}$ caudal angulation) based on an entry point $2-\mathrm{mm}$ cephalad to the $\mathrm{C} 0-\mathrm{C} 1$ joint to determine the hypoglossal canal compromise cranially or the atlantooccipital joint violation caudally (Fig. 3A-C).

\section{Feasibility of placement of occipital condyle screw in Indian population}

In the reconstructed oblique sagittal plane, the atlantooccipital joint line (AOJL) was drawn connecting the highest points of the anterior and posterior edges of the atlantooccipital joint. The effective height $(\mathrm{EH})$ available for passage of a 3.5-mm diameter OCS through the corridor beneath the hypoglossal canal and above the atlantooccipital joint was measured between the inferior border of the hypoglossal canal and above AOJL (Fig. 4A). Allowing a safety margin of $1 \mathrm{~mm}$, the percentage of popula-
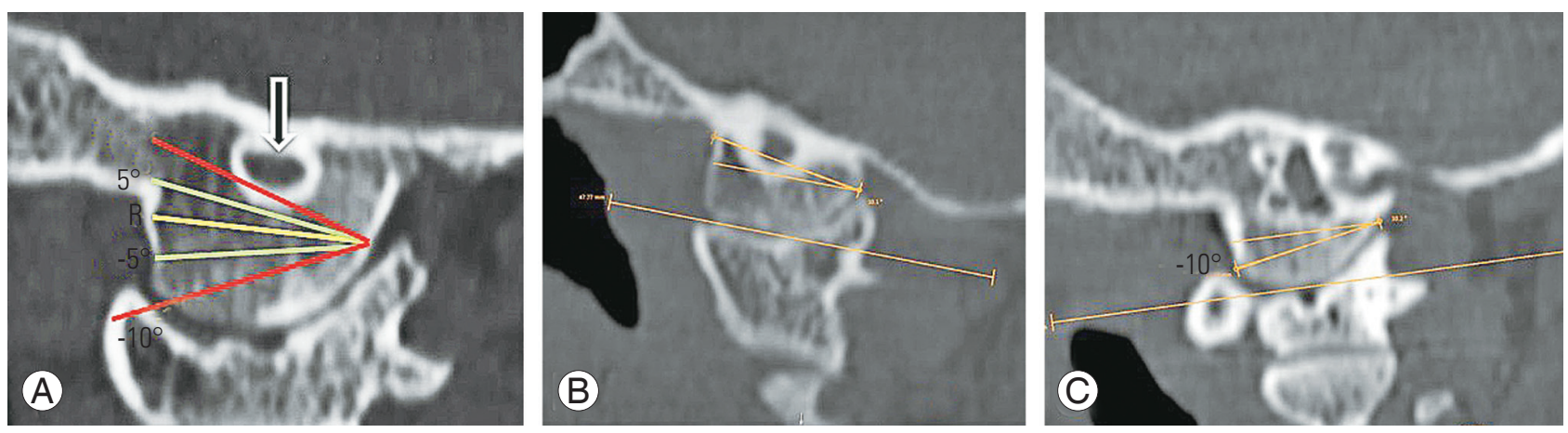

Fig. 3. (A) Reconstructed sagittal CT images of the occipitocervical junction (bone window) showing virtual planes of screw insertion for $10^{\circ} \mathrm{cranial}$, $5^{\circ}$ cranial, $5^{\circ}$ caudal, and $10^{\circ}$ caudal angulations with respect to a reference line " $\mathrm{R}$ " drawn parallel to the skull base. (B) Sagittal CT showing hypoglossal canal compromise by a $10^{\circ}$ cranial screw trajectory. (C) Sagittal CT showing atlantooccipital joint violation by a $10^{\circ}$ caudal screw trajectory. CT, computed tomography.
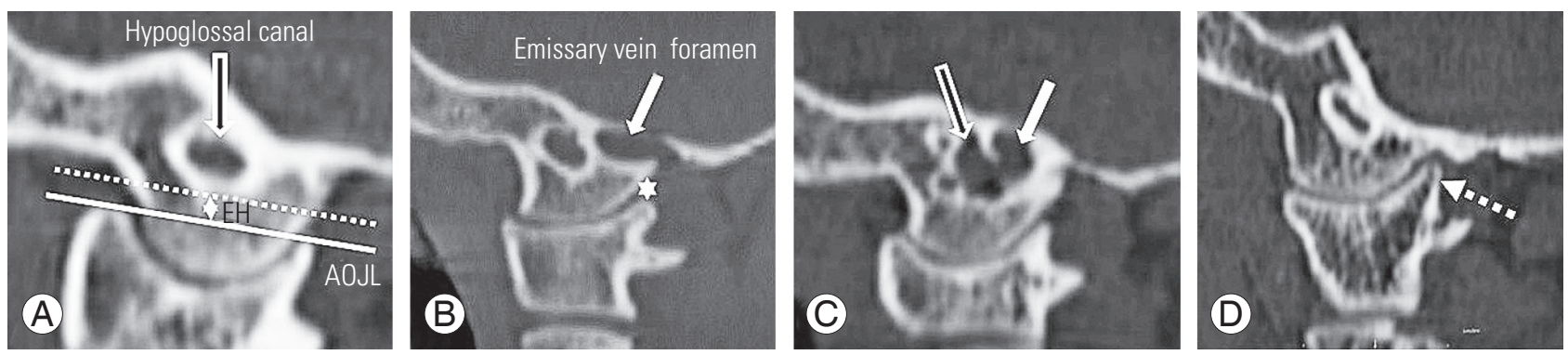

Fig. 4. (A) Reconstructed sagittal CT image of the occipitocervical junction (bone window) showing measurement of EH available (double-headed arrow) for occipital condyle screw placement. AOJL indicates the line connecting the highest points of the anterosuperior and posterosuperior rim of the C1 lateral mass. (B) Sagittal CT images depicting the presence of an aberrant canal for the posterior fossa emissary vein (white arrow) close to the screw entry point (white asterisk), and (C) abnormal communication between the emissary vein foramen and hypoglossal canal and its location along the screw path posing a risk of significant neurovascular injury (arrows). (D) Sagittal CT image showing the screw entry point covered by overgrowth of the posterosuperior rim of the C1 lateral mass (white dotted arrow). CT, computed tomography; A0JL, atlantooccipital joint line; EH, effective height. 
tion with a safety corridor of at least $4.5 \mathrm{~mm}$ to permit an OCS safely was determined. We analyzed any variations in anatomy that could hinder screw placement.

\section{Measurement of optimal sagittal angle and safe screw lengths for $\mathrm{C0}-\mathrm{C} 1$ transarticular screw placement}

To determine the optimal sagittal angle of the $\mathrm{C} 0-\mathrm{C} 1$ transarticular screw, two possible entry points described in the literature were chosen [26]: at the junction of the posterior arch of $\mathrm{C} 1$ and the midpoint of the $\mathrm{C} 1$ lateral mass (the junctional entry point technique) (Fig. 5A), and at the midpoint of the caudal margin of the $\mathrm{C} 1$ posterior arch (caudal C1 arch entry point) (Fig. 5C). The anterosuperior corner of $\mathrm{OC}$ was the targeted exit point, and the screw was directed across the $\mathrm{C} 0-\mathrm{C} 1$ joint in a convergent trajectory (angulated $10^{\circ}$ medially) to avoid the hypoglossal canal and to obtain adequate screw-bone purchase. The sagittal angulation of the $\mathrm{C} 0-\mathrm{C} 1$ transarticular screw and the screw length for bicortical purchase was measured for each entry point (Fig. 5).

\section{Statistical analysis}

Analysis was performed using SPSS software ver. 17.0 (SPSS Inc., Chicago, IL, USA). Descriptive statistics including the mean, standard deviation, and 95\% confidence interval were calculated for all measurements. Sex differences and differences between right- and left-side measurements were determined using $t$-tests and were considered statistically significant at $p<0.05$. The analysis of variance test was used to analyze variations in morphometric measurements across different age groups.

\section{Results}

The study sample consisted of 70 patients (35 males and 35 females) with a mean age of $42.1 \pm 14.6$ years (range,
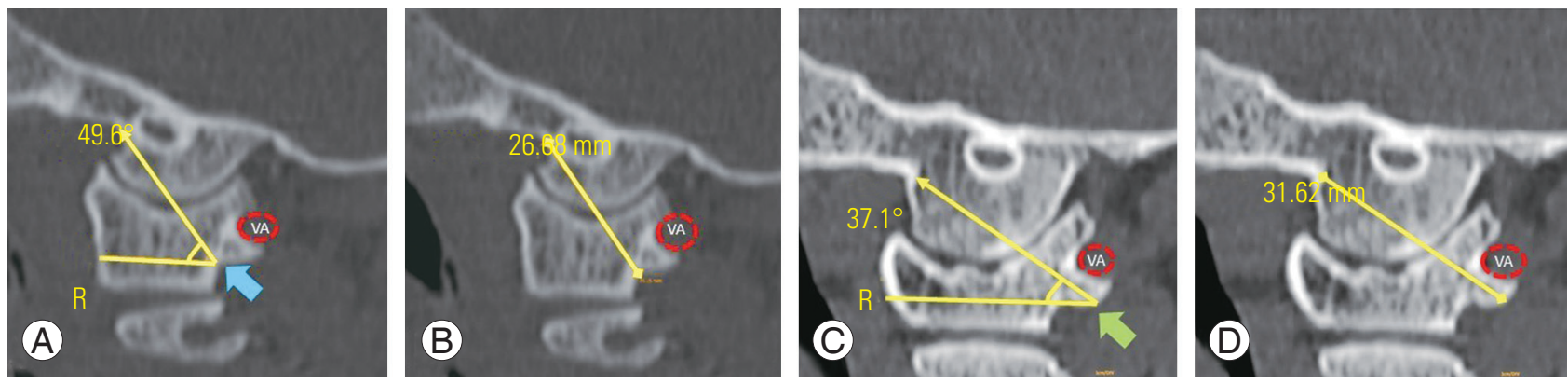

Fig. 5. Reconstructed sagittal computed tomography images of the occipitocervical junction showing measurements of the optimal sagittal angle and screw length for $\mathrm{CO}-\mathrm{C} 1$ transarticular screw techniques. (A, B) The measurements of the optimal sagittal angle and screw length for the junctional entry point technique (Technique 1) (broad blue arrow). (C, D) The measurements of the optimal sagittal angle and screw length for the caudal $\mathrm{C} 1$ arch entry point technique (Technique 2) (broad green arrow). $\mathrm{R}$ is the reference line parallel to the inferior margin of the C1 posterior arch. VA, vertebral artery.

Table 1. Results of morphometric measurements on occipital condyles in Indian population

\begin{tabular}{|c|c|c|c|c|}
\hline Morphometric parameters & Males & Females & $p$-value & Total \\
\hline OC length (mm) & $19.5 \pm 2.5(4.5-24.3)$ & $18.1 \pm 1.8(14.1-23.0)$ & $<0.001^{* * *}$ & $18.8 \pm 2.3(4.5-24.3)$ \\
\hline OC width (mm) & $10.5 \pm 1.8(4.6-14.8)$ & $10.0 \pm 1.2(7.2-12.8)$ & 0.041 & $10.3 \pm 1.5(4.6-14.8)$ \\
\hline Axial condyle angle $\left(^{\circ}\right)$ & $31.1 \pm 4.4(22.0-42.9)$ & $30.7 \pm 3.3(23.3-45.2)$ & 0.612 & $30.9 \pm 3.9(22.0-45.2)$ \\
\hline Hypoglossal canal distance $(\mathrm{mm})$ & $9.9 \pm 1.5(6.4-13.6)$ & $8.2 \pm 1.3(6.0-11.4)$ & $<0.001^{* * *}$ & $9.1 \pm 1.6(6.0-13.6)$ \\
\hline Anterior condyle height ${ }^{\text {al }}(\mathrm{mm})$ & $14.2 \pm 2.1(10.4-19.9)$ & $12.3 \pm 2(8.7-19.9)$ & $<0.001^{* * *}$ & $13.2 \pm 2.2(8.7-19.9)$ \\
\hline Posterior condyle height ${ }^{\mathrm{a})}(\mathrm{mm})$ & $9.0 \pm 1.7(5.8-13.7)$ & $7.9 \pm 1.4(4.4-13.7)$ & $<0.001^{* * *}$ & $8.5 \pm 1.6(4.4-13.7)$ \\
\hline OC height medial ${ }^{\mathrm{b})}(\mathrm{mm})$ & $9.6 \pm 1.5(5.9-12.5)$ & $8.3 \pm 1.1(3.2-10.7)$ & $<0.001^{* * *}$ & $8.9 \pm 1.4(3.2-12.5)$ \\
\hline OC height lateral ${ }^{\mathrm{b})}(\mathrm{mm})$ & $4.6 \pm 1.3(2.4-8.2)$ & $4.1 \pm 0.9(2.2-7.0)$ & 0.011 & $4.4 \pm 1.2(2.2-8.2)$ \\
\hline
\end{tabular}

Values are presented as mean \pm standard deviation (range).

OC, occipital condyle.

${ }^{* * *} p<0.001 .{ }^{a}$ In sagittal plane. ${ }^{b}$ In coronal plane. 

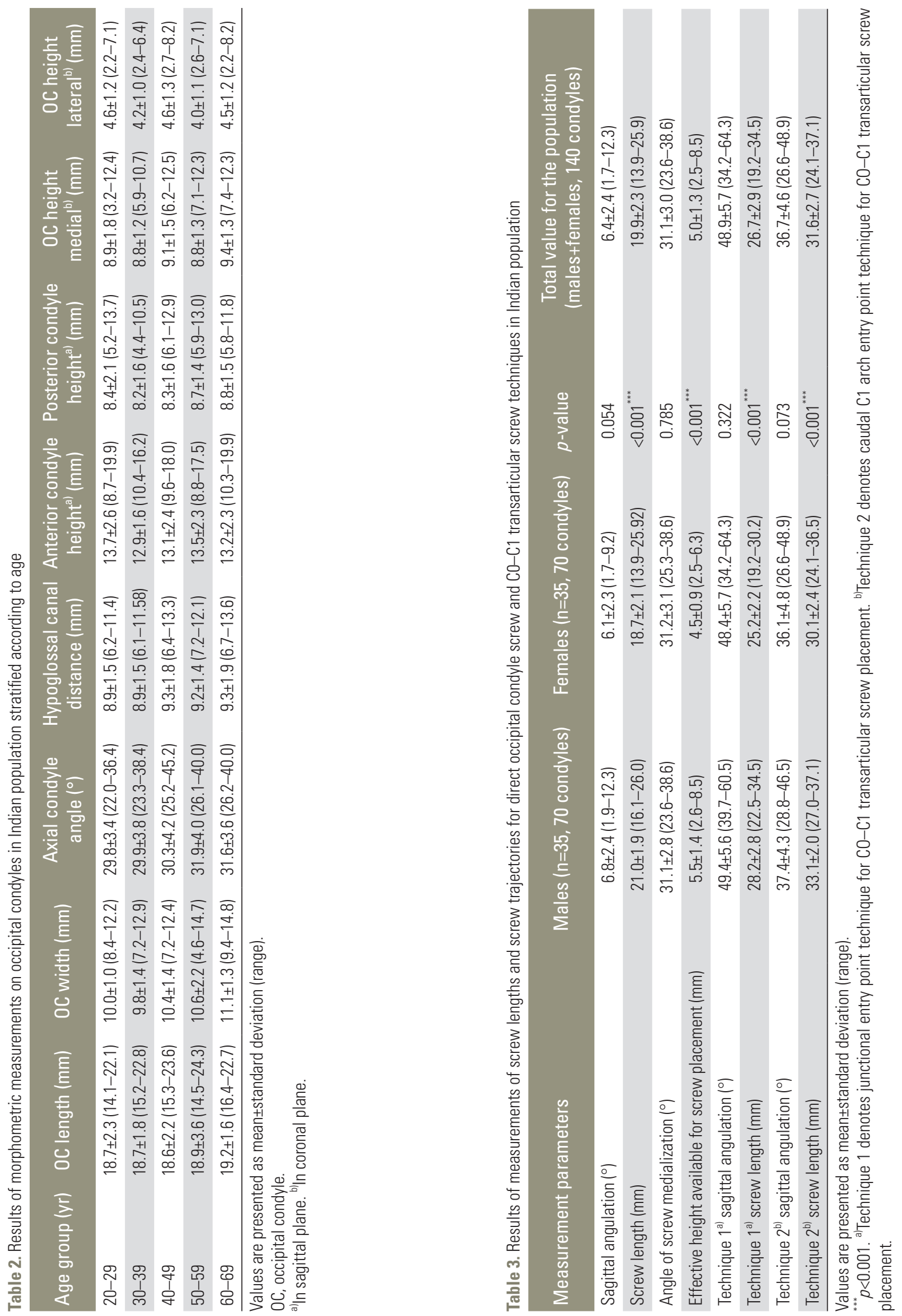
18-65 years). Table 1 presents the results of morphometric measurements of OCs. There were no significant differences with respect to OCL, OCW, height, and axial condyle angle between the right and left sides. The OCL, height, and hypoglossal canal distance were significantly greater in males than in females $(p<0.001)$. Table 2 presents the morphometric measurements of OCs across different age groups. There were no significant changes in the morphometric parameters (OCL, OCW, height, axial condyle angle, and hypoglossal canal distance) between the different age groups and with advancing age.

Table 3 presents the OCS and $\mathrm{C} 0-\mathrm{C} 1$ transarticular screw trajectories and lengths. The OCS length was significantly longer in males than in females $(p<0.001)$. The EH available for screw passage was slightly greater in males than in females $(p<0.001)$. More importantly, in $27.6 \%$ of the condyles, EH available for OCS passage was $<4.5 \mathrm{~mm}$, thus making screw placement uncertain. The safe permissible craniocaudal angulations for OCS showed that an angulation from $0^{\circ}$ to $5^{\circ}$ cranially was the only trajectory without any anatomical compromise.

A venous channel for the posterior condylar emissary veins was found near the entry point or along the path of screw passage unilaterally in $14 \%$ and bilaterally in $12 \%$ of the population (Fig. 4B, C). Another interesting finding was that the entry point was covered by posterosuperior projection of the C1 lateral mass unilaterally in $12 \%$ and bilaterally in $10 \%$ of the population, which caused difficulty in accessing the screw entry point (Fig. 4D).
The screw lengths for both techniques of $\mathrm{C} 0-\mathrm{C} 1$ transarticular screw insertion were significantly longer in males than in females $(p<0.001)$.

\section{Discussion}

During the past decades, the occipital squama was primarily used for the surgical fixation of occipitocervical instability. Although there are many options available for caudal fixation in OCF, the options for cephalad anchorage are limited by the complex OCJ anatomy and the risk of injury to important anatomical structures. With the huge advancements in spinal instrumentation, intraoperative fluoroscopy, and the availability of neuronavigation, there has been more interest in identifying new points of fixation at OCJ. Two OC-based techniques, namely, direct OCS $[9,10]$ and $\mathrm{C} 0-\mathrm{C} 1$ transarticular screw fixation $[8]$, have been described as viable options for cranial anchorage.

Although several morphometric, cadaveric and biomechanical studies have established the feasibility, safety, and biomechanical stability of these techniques in different populations $[9,10,13-18,26-28]$, their feasibility and safety in Indian population has yet to be investigated. Even with supportive technology, such as intraoperative imaging and navigation systems, accurate knowledge of the dimensions and orientation of OC and its critical neurovascular neighborhood is important for using these novel techniques. Therefore, we investigated the feasibility and safety

Table 4. Comparison of Indian occipital condyle dimensions with other populations

\begin{tabular}{|c|c|c|c|c|c|}
\hline Researchers & Year & Population & Length (mm) & Width (mm) & Height (mm) \\
\hline Present study & 2016 & Indian & $18.8 \pm 2.3$ & $10.3 \pm 1.5$ & $9.1 \pm 1.6$ \\
\hline Zhou et al. [33] & 2016 & Chinese & $22.2 \pm 1.7$ & $12.1 \pm 1$ & $9.4 \pm 1.5$ \\
\hline El-Gaidi et al. [13] & 2014 & Egyptian & $24.2 \pm 3.6$ & $14.2 \pm 1.9$ & $10.7 \pm 2$ \\
\hline Ozer et al. [14] & 2011 & Turkish & 23.95 & 11.3 & - \\
\hline Le et al. [17] & 2011 & American & 22.4 & 11.2 & 9.9 \\
\hline Hong et al. [25] & 2011 & American & $22.9 \pm 2.5$ & $14.1 \pm 1.8$ & \\
\hline Kizilkanat et al. [27] & 2006 & Turkish & 24.5 & 13.1 & - \\
\hline Naderi et al. [28] & 2005 & Turkish & 23.6 & 10.5 & 9.2 \\
\hline Bozbuga et al. [29] & 1999 & Turkish & 23.1 & 11.3 & - \\
\hline Lang and Hornung [30] & 1993 & German & 22.9 & - & - \\
\hline Guidotti [31] & 1984 & Italian & 23.7 & - & - \\
\hline Oliver [32] & 1975 & French & 23.7 & 11.5 & 8.8 \\
\hline
\end{tabular}

Values are presented as mean \pm standard deviation or mean, unless otherwise stated. 
of these techniques in Indian population.

This study described the morphological characteristics of Indian OCs. There are significant differences in OC morphology between Indian and other study populations (Table 4) [13,14,17,25,27-33]. These variations could be because of different methods of data assimilation and genetic endowments of the different populations. The length, width, and height of OCs in our Indian population were smaller than those in other populations (Table 4). This finding has significant implications because it may influence the size of screws that can be placed in OCs. Furthermore, the study provides a reference database of morphometrics of Indian OCs, which could be useful in designing implants for the same. The existing data on morphometry of Indian OCs are primarily based on manual or digitalized measurements on cadaveric or dry skulls [18-23]. The only available CT-based study was conducted in a small sample [24]. In the previous Indian studies, the samples were not uniformly distributed across all age groups or stratified by sex to obtain normative reference data for the general population. In the present study, we ensured that the sample was equally distributed across all age groups to be representative of the general population. The study also showed that there were no significant changes in morphometric parameters between the different age groups (20-29, 30-39, 40-49, 50-59, and 60-69 years) and with advancing age.

An analysis of EH available for placing a $3.5-\mathrm{mm}$ diameter screw into $\mathrm{OC}$ to allow a safety margin of $1 \mathrm{~mm}$ showed that OCS can be safely placed in $72.4 \%$ of Indians. However, $27.6 \%$ of the population could not safely accommodate a $3.5-\mathrm{mm}$ diameter screw because $\mathrm{EH}$ was $<4.5$ $\mathrm{mm}$. In these patients, $\mathrm{C} 0-\mathrm{C} 1$ transarticular screw fixation could be a safer option.

Our results allowed for defining the safe trajectories and screw lengths for direct OCS placement in Indians. The longest possible OCS length for bicortical purchase was $19.9 \pm 2.3 \mathrm{~mm}$. This finding was comparable to that of the study by Zhou et al. [33] in a Chinese population (19.3 \pm 1.9 $\mathrm{mm}$ ) but was significantly shorter than that described in Western populations $[9,10,13]$. We also found significant differences in screw insertion trajectories between our Indian population and the other populations $[9,10,13,33]$.

An analysis of safe craniocaudal angulation showed that a cranial or caudal angulation of $\geq 10^{\circ}$ had the highest risk of violating the hypoglossal canal (52/140 condyles) or C0-C1 joint (29/140 condyles), respectively, and should be avoided. An angulation from $0^{\circ}$ to $5^{\circ}$ cranially was the safest for placing OCS without compromising the hypoglossal canal or atlantooccipital joint. Although a $0^{\circ}$ trajectory in the sagittal plane would be the safest theoretically, it would not fit the longest possible screw. A cranial angulation would facilitate a longer screw with a better hold.

An ideal entry point for OCS would be at mid-condylar level and medial to the condylar fossa, 5-mm lateral to the posteromedial border of the condyle at the midpoint of its posterior surface, 2-mm cephalad to the $\mathrm{C} 0-\mathrm{C} 1$ joint, and aimed to exit at the anterosuperior margin of OC. The medial angulation should be ideally parallel to the long axis of OC, which is typically between $23^{\circ}$ and $38^{\circ}$ medially in Indians. The maximum permissible sagittal angulation with the screw stopping $2 \mathrm{~mm}$ below the hypoglossal canal is $6.4^{\circ} \pm 2.3^{\circ}$ cranially.

The mean sagittal (cranial) angulation of C0-C1 transarticular screw was $48.9^{\circ} \pm 5.7^{\circ}$ at the junctional entry point, which was significantly greater $(p<0.001)$ than the mean sagittal angulation of $\mathrm{C} 0-\mathrm{C} 1$ transarticular screw at the caudal $\mathrm{C} 1$ arch entry point $\left(36.7^{\circ} \pm 4.6^{\circ}\right)$. Similarly, the screw lengths for the caudal arch entry technique (31.6 \pm 2.7 $\mathrm{mm}$ ) were significantly longer than those for junctional entry point technique $(26.7 \pm 2.9 \mathrm{~mm}, p<0.001)$. Compared with those in previous studies on other populations $[16,25,34]$, the sagittal trajectory and screw lengths for these techniques were different in Indians. We observed that the caudal $\mathrm{C} 1$ arch entry technique had a high risk of vertebral artery injury and is best avoided.

Intraoperative navigation may be well suited for screw insertion in complex scenarios, such as OCJ instability. However, it is expensive and not widely available. Although intraoperative fluoroscopy may be a useful aid, the complex anatomy inherent to OCJ may be disorienting at times even for an experienced spine surgeon. Therefore, having an idea of the normative values of screw trajectories and screw lengths of the general population will help in avoiding complications.

The results presented in this study can serve as a useful reference database for these novel OCF techniques (OCS and $\mathrm{C} 0-\mathrm{C} 1$ transarticular screw insertion) in Indian populations and should prove valuable in safe and effective placement of screws.

A limitation of the study is that we did not analyze the relationship between the vertebral artery and the screw entry point, which would require the use of 3D-CT angi- 
ography. A 3D-CT angiographic analysis of the vertebral artery course and its spatial relationship to the entry point is essential before attempting instrumentation at the OC junction.

\section{Conclusions}

The morphometrics of OCs and the trajectories and screw lengths for OC-based OCF were significantly different between Indian population and other populations. We think that OCS and $\mathrm{C} 0-\mathrm{C} 1$ transarticular screws are feasible options in Indian population and could be a useful alternative or salvage option in select cases, wherein occipital squama-based fixation is not feasible. However, because of the presence of aberrant bony and vascular anatomy in a considerable percentage of the population, we recommend a detailed evaluation of thin-slice CT, including 3D-CT angiography, before attempting these new OCF techniques. Intraoperative navigation, if available, will be a valuable aid in safely placing these screws. Nevertheless, the trajectories and safe screw lengths presented in our study should provide a valuable baseline guide in performing OC-based craniovertebral fixations safely and effectively under fluoroscopic guidance.

\section{Conflict of Interest}

No potential conflict of interest relevant to this article was reported.

\section{Acknowledgments}

The study was funded by Ganga Orthopaedic Research and Education Foundation (GOREF), Ganga Hospital, Coimbatore, India. We thank GOREF for funding this study.

\section{References}

1. Stock GH, Vaccaro AR, Brown AK, Anderson PA. Contemporary posterior occipital fixation. J Bone Joint Surg Am 2006;88:1642-9.

2. Winegar CD, Lawrence JP, Friel BC, et al. A systematic review of occipital cervical fusion: techniques and outcomes. J Neurosurg Spine 2010;13:5-16.

3. Smucker JD, Sasso RC. The evolution of spinal instrumentation for the management of occipital cer- vical and cervicothoracic junctional injuries. Spine (Phila Pa 1976) 2006;31(11 Suppl):S44-52.

4. Vender JR, Rekito AJ, Harrison SJ, McDonnell DE. The evolution of posterior cervical and occipitocervical fusion and instrumentation. Neurosurg Focus 2004;16:E9.

5. Hwang SW, Gressot LV, Chern JJ, Relyea K, Jea A. Complications of occipital screw placement for occipitocervical fusion in children. J Neurosurg Pediatr 2012;9:586-93.

6. Randazzo CG, LeBude B, Ratliff J, Harrop J. Occiputcervical fixation. In: Patel VV, Burger E, Brown C, editors. Spine trauma: surgical techniques. Berlin: Springer-Verlag; 2010. p.119-27.

7. De Oliveira E, Rhoton AL Jr, Peace D. Microsurgical anatomy of the region of the foramen magnum. Surg Neurol 1985;24:293-352.

8. Grob D. Transarticular screw fixation for atlanto-occipital dislocation. Spine (Phila Pa 1976) 2001;26:7037.

9. Uribe JS, Ramos E, Vale F. Feasibility of occipital condyle screw placement for occipitocervical fixation: a cadaveric study and description of a novel technique. J Spinal Disord Tech 2008;21:540-6.

10. La Marca F, Zubay G, Morrison T, Karahalios D. Cadaveric study for placement of occipital condyle screws: technique and effects on surrounding anatomic structures. J Neurosurg Spine 2008;9:347-53.

11. Uribe JS, Ramos E, Baaj A, Youssef AS, Vale FL. Occipital cervical stabilization using occipital condyles for cranial fixation: technical case report. Neurosurgery 2009;65:E1216-7.

12. Gonzalez LF, Klopfenstein JD, Crawford NR, Dickman CA, Sonntag VK. Use of dual transarticular screws to fixate simultaneous occipitoatlantal and atlantoaxial dislocations. J Neurosurg Spine 2005;3:318-23.

13. El-Gaidi MA, Eissa EM, El-Shaarawy EA. Free-hand placement of occipital condyle screws: a cadaveric study. Eur Spine J 2014;23:2182-8.

14. Ozer MA, Celik S, Govsa F, Ulusoy MO. Anatomical determination of a safe entry point for occipital condyle screw using three-dimensional landmarks. Eur Spine J 2011;20:1510-7.

15. Lee HJ, Choi DY, Shin MH, Kim JT, Kim IS, Hong JT. Anatomical feasibility for safe occipital condyle screw fixation. Eur Spine J 2016;25:1674-82.

16. Senoglu M, Safavi-Abbasi S, Theodore N, Crawford 
NR, Sonntag VK. Feasible and accurate occipitoatlantal transarticular fixation: an anatomic study. Neurosurgery 2010;66(3 Suppl Operative):173-7.

17. Le TV, Vivas AC, Baaj AA, Vale FL, Uribe JS. Optimal trajectory for the occipital condyle screw. J Spinal Disord Tech 2014;27:93-7.

18. Tale AK, Kulkarni PR, Shaikh SI, Fupare SS. Morphometric study of the occipital condyle and its surgical importance. Int J Anat Res 2016;4:1802-5.

19. Saluja S, Das SS, Vasudeva N. Morphometric analysis of the occipital condyle and its surgical importance. J Clin Diagn Res 2016;10:AC01-4.

20. Sahoo S, Giri SK, Panda SK, Panda P, Sahu MC, Mohapatra C. Morphometric analysis of the foramen magnum and the occipital condyles. Int J Pharm Sci Rev Res 2015;33:198-204.

21. Kalthur SG, Padmashali S, Gupta C, Dsouza AS. Anatomic study of the occipital condyle and its surgical implications in transcondylar approach. J Craniovertebr Junction Spine 2014;5:71-7.

22. Kavitha S, Chandrasekaran S, Anand A, Shanthi KC. Morphometric study of occipital condyles in adult human skulls. Int J Curr Res Rev 2013;5:31-4.

23. Muthukumar N, Swaminathan R, Venkatesh G, Bhanumathy SP. A morphometric analysis of the foramen magnum region as it relates to the transcondylar approach. Acta Neurochir (Wien) 2005;147:889-95.

24. Agnihotri G, Mahajan D, Sheth A. An anatomical perspective of human occipital condyles and foramen magnum with neurosurgical correlates. J Evol Med Dent Sci 2014;3:4497-504.

25. Hong JT, Takigawa T, Sugisaki K, Espinoza Orias AA,
Inoue N, An HS. Biomechanical and morphometric evaluation of occipital condyle for occipitocervical segmental fixation. Neurol Med Chir (Tokyo) 2011;51:701-6.

26. Uribe JS, Ramos E, Youssef AS, et al. Craniocervical fixation with occipital condyle screws: biomechanical analysis of a novel technique. Spine (Phila Pa 1976) 2010;35:931-8.

27. Kizilkanat ED, Boyan N, Soames R, Oguz O. Morphometry of the hypoglossal canal, occipital condyle, and foramen magnum. Neurosurg Q 2006;16:121-5.

28. Naderi S, Korman E, Citak G, et al. Morphometric analysis of human occipital condyle. Clin Neurol Neurosurg 2005;107:191-9.

29. Bozbuga M, Ozturk A, Bayraktar B, et al. Surgical anatomy and morphometric analysis of the occipital condyles and foramen magnum. Okajimas Folia Anat Jpn 1999;75:329-34.

30. Lang J, Hornung G. The hypoglossal channel and its contents in the posterolateral access to the petroclival area. Neurochirurgia (Stuttg) 1993;36:75-80.

31. Guidotti A. Morphometrical considerations on occipital condyles. Anthropol Anz 1984;42:117-9.

32. Olivier G. Biometry of the human occipital bone. J Anat 1975;120(Pt 3):507-18.

33. Zhou J, Espinoza Orias AA, Kang X, et al. CT-based morphometric analysis of the occipital condyle: focus on occipital condyle screw insertion. J Neurosurg Spine 2016;25:572-9.

34. Lee KM, Yeom JS, Lee JO, et al. Optimal trajectory for the atlantooccipital transarticular screw. Spine (Phila Pa 1976) 2010;35:1562-70. 